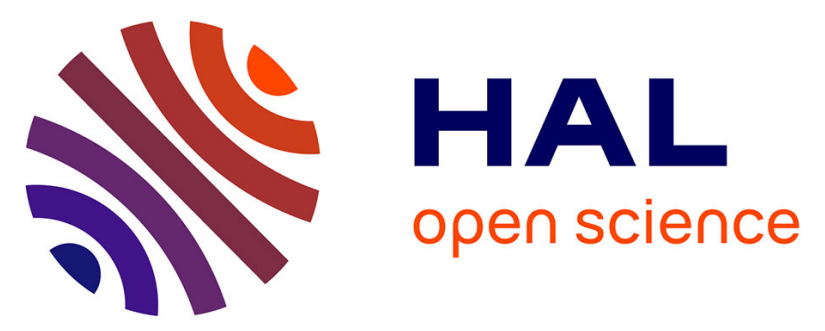

\title{
A single-center study to evaluate the efficacy of a fetal urine peptide signature predicting postnatal renal outcome in fetuses with posterior urethral valves
}

Bénédicte Buffin-Meyer, Marcin Tkaczyk, Malgorzata Stańczyk, Benjamin

Breuil, Justyna Siwy, Krzysztof Szaflik, Tomasz Talar, Justyna Wojtera,

Waldemar Krzeszowski, Stephane Decramer, et al.

\section{To cite this version:}

Bénédicte Buffin-Meyer, Marcin Tkaczyk, Malgorzata Stańczyk, Benjamin Breuil, Justyna Siwy, et al.. A single-center study to evaluate the efficacy of a fetal urine peptide signature predicting postnatal renal outcome in fetuses with posterior urethral valves. Pediatric Nephrology, 2020, 35 (3), pp.469-475. 10.1007/s00467-019-04390-9 . inserm-02481274

HAL Id: inserm-02481274 https://www.hal.inserm.fr/inserm-02481274

Submitted on 17 Feb 2020

HAL is a multi-disciplinary open access archive for the deposit and dissemination of scientific research documents, whether they are published or not. The documents may come from teaching and research institutions in France or abroad, or from public or private research centers.
L'archive ouverte pluridisciplinaire HAL, est destinée au dépôt et à la diffusion de documents scientifiques de niveau recherche, publiés ou non, émanant des établissements d'enseignement et de recherche français ou étrangers, des laboratoires publics ou privés. 


\section{Pediatric Nephrology}

\section{A single center study to evaluate the efficacy of a fetal urine peptide signature predicting postnatal renal outcome in fetuses with posterior urethral valves \\ --Manuscript Draft--}

\begin{tabular}{|c|c|c|}
\hline Manuscript Number: & \multicolumn{2}{|l|}{ PNEP-D-19-00360R1 } \\
\hline Full Title: & \multicolumn{2}{|c|}{$\begin{array}{l}\text { A single center study to evaluate the efficacy of a fetal urine peptide signature } \\
\text { predicting postnatal renal outcome in fetuses with posterior urethral valves }\end{array}$} \\
\hline Article Type: & \multicolumn{2}{|l|}{ Original Article } \\
\hline Corresponding Author: & \multicolumn{2}{|l|}{$\begin{array}{l}\text { Joost Schanstra } \\
\text { Inserm } \\
\text { Toulouse, Midi-Pyrenees FRANCE }\end{array}$} \\
\hline \multicolumn{3}{|l|}{$\begin{array}{l}\text { Corresponding Author Secondary } \\
\text { Information: }\end{array}$} \\
\hline Corresponding Author's Institution: & \multicolumn{2}{|l|}{ Inserm } \\
\hline \multicolumn{3}{|l|}{$\begin{array}{l}\text { Corresponding Author's Secondary } \\
\text { Institution: }\end{array}$} \\
\hline First Author: & \multicolumn{2}{|l|}{ Bénédicte Buffin-Meyer } \\
\hline \multicolumn{3}{|l|}{ First Author Secondary Information: } \\
\hline \multirow[t]{12}{*}{ Order of Authors: } & \multicolumn{2}{|l|}{ Bénédicte Buffin-Meyer } \\
\hline & \multicolumn{2}{|l|}{ Marcin Tkaczyk } \\
\hline & \multicolumn{2}{|l|}{ Małgorzata Stańczyk } \\
\hline & \multicolumn{2}{|l|}{ Benjamin Breuil } \\
\hline & \multicolumn{2}{|l|}{ Justyna Siwy } \\
\hline & \multicolumn{2}{|l|}{ Krzysztof Szaflik } \\
\hline & \multicolumn{2}{|l|}{ Tomasz Talar } \\
\hline & \multicolumn{2}{|l|}{ Justyna Wojtera } \\
\hline & \multicolumn{2}{|l|}{ Waldemar Krzeszowski } \\
\hline & \multicolumn{2}{|l|}{ Stéphane Decramer } \\
\hline & \multicolumn{2}{|l|}{ Julie Klein } \\
\hline & \multicolumn{2}{|l|}{ Joost Schanstra } \\
\hline \multicolumn{3}{|c|}{ Order of Authors Secondary Information: } \\
\hline \multirow[t]{3}{*}{ Funding Information: } & $\begin{array}{l}\text { Polish Mother's Memorial Hospital } \\
\text { (2016/IV/54-GW) }\end{array}$ & Dr Marcin Tkaczyk \\
\hline & $\begin{array}{l}\text { Fondation pour la Recherche Médicale } \\
\text { (DEQ20170336759) }\end{array}$ & Dr. Joost Schanstra \\
\hline & $\begin{array}{l}\text { Agence de la Biomedicine } \\
\text { (Not applicable) }\end{array}$ & Dr Bénédicte Buffin-Meyer \\
\hline Abstract: & \multicolumn{2}{|c|}{$\begin{array}{l}\text { Background - } \\
\text { Posterior urethral valves (PUV) accounts for } 17 \% \text { of pediatric renal failure. The } \\
\text { management of pregnancies involving fetuses with PUV is hampered by the fact that } \\
\text { current clinical parameters obtained from fetal ultrasound and/or fetal urine } \\
\text { biochemistry are insufficient to predict postnatal renal function. We previously have } \\
\text { developed a fetal urine peptide signature (12PUV) that predicted with high precision } \\
\text { postnatal renal failure at } 2 \text { years of age in fetuses with PUV. Here we evaluated the } \\
\text { accuracy of this signature to predict postnatal renal outcome in fetuses with PUV in an } \\
\text { independent single center study.Methods - }\end{array}$} \\
\hline
\end{tabular}


Thirty three woman carrying fetuses with suspected PUV were included. Twenty five fetuses received vesicoamniotic shunts (VAS) during pregnancy. PUV was confirmed postnatally in 23 patients. Of those 23 fetuses, 2 were lost in follow-up. Four and 3 patients died in the pre- and perinatal-period, respectively. Follow-up renal function at 6 month of age was obtained for the remaining 14 patients. The primary outcome was early renal failure, defined by an eGFR $<60 \mathrm{~mL} / \mathrm{min} / 1.73$ before 6 months of age or preor perinatal death. Results -

The peptide signature predicted postnatal renal outcome in postnatally confirmed PUV fetuses with an AUC of $0.94(95 \% \mathrm{Cl}: 0.74-1.0)$ and an accuracy of $90 \%(95 \% \mathrm{Cl}$ : $78-$ 100). The signature predicted postnatal renal outcome for the suspected PUV cases with an AUC of $0.89(95 \% \mathrm{Cl}: 0.72-0.97)$ and an accuracy of $84 \%(95 \% \mathrm{Cl}$ : $71-$ 97). Conclusion -

This single center study confirms the predictive power of the previously identified 12PUV fetal urinary peptide signature.

\section{Response to Reviewers:}

Reviewers' comments:

\section{Reviewer \#1:}

R1Q1: The authors should supply more clinical data on the patients that died in the perinatal period. Especially cause and time of death should be provided. The authors stated that cause of death was most likely severe renal disease but hypoplasia of the lungs may have accounted for several deaths in the perinatal period. Please clarify. R1A1: Thank you for this comment.

- First of all we would like to correct the numbers of patients that died in the perinatal period (defined by 22 gestational weeks until 7 completed days after birth) which we did not define correctly in the first version of the manuscript. Taken into account this gestational age-range, only 3 patients died in the perinatal period. Hence this was corrected in the text on page 6 and in Table 1.

- Indeed we obtained some information on the non-renal causes potentially involved in the death of those 3 patients in the perinatal period: "Three patients died in the perinatal period ( 2 patients died within the first 12 hours from delivery and 1 neonate died after 64 hours from delivery). These 3 patients had pulmonary insufficiency, renal insufficiency, secondary cardiac insufficiency with no-response to resuscitation (ventilation) and vasopressors, and neurological complications (intracranial hemorrhage)." This has been added to the results section on page 6 and the comment on the absence of clinical data in the perinatal period was deleted from the discussion section. However no information on the prenatal death other than confirmation of PUV was obtained.

R1Q2: Although the AUC of the ROC analysis carries the highest informative value, the authors should also provide sensitivity and specificity as achieved by the test's cut-off value as used in the results section.

R1A2: Sensitivity and specificity has been added to the results section using the cut-off values of the original STM study on page 6 and 7 .

Reviewer \#2:

R2Q1: Introduction: Clarify how better predictors may affect management (prenatal counseling, postnatal follow up)

R2A1: We have introduced a paragraph in the introduction describing how improved prediction may affect management on page 3 .

R2Q2: Methods: How was simple size determined

R2A2: Thank you for this important remark that made us reconsider some of the wording in the manuscript.

We did not determine a sample size before starting the study, as the current study was an excellent opportunity to perform a preliminary but small independent "pre-validation" of the signature.

As mentioned in the discussion of the manuscript, a large-scale international multicenter study, called ANTENATAL, is currently ongoing (finishing in 2023) aiming the multicenter validation of the 12PUV fetal urine peptide signature. The power calculation including loss of follow-up and refusal to participate in the ANTENATAL study estimated screening of $\sim 400$ patients with PUV for this study. This number is 
clearly not reachable by a single center for a rare disease such as PUV. Therefore we believe we have not correctly used the word "validation" throughout the current study since this should be reserved for the ANTENATAL study.

As indicated in the present work, the signature displayed similar efficacy in the current single center study to predict outcome compared to the initial STM study. We therefore omitted the word "validation" throughout the revised manuscript and replaced it by "study of efficacy" or similar wording.

R2Q3: Results: What is the value of including infants who didn't have confirmed PUV in the second analysis, this seems to be unnecessary.

R2A3: We respectfully disagree with this reviewer that including infants without confirmed PUV is unnecessary. In the clinical situation, where the use of the 12PUV signature is envisaged, management of the disease and parental counselling occur in the prenatal period where PUV is suspected but not yet confirmed (unless laser ablation of the valves is performed in utero). In most cases the presence of valves is only confirmed after birth. We believe that this justification is correctly worded in the discussion section but is only shortly described in the section where we present the results which might have not fully convinced this reviewer. Therefore, we have added an additional justification to the results section as well on page 7 .

R2Q4: Discussion: "The 12PUV fetal urine peptide signature-based prediction tends to confirm this by displaying absence of differences in the predictive capacity of the signature between patients that underwent VAS or not." This study was not intended to evaluate that outcome, besides it is a very small number for comparison.

R2A5: Although we agree that the study is small scale we believe that it is worth to point out that the majority of the patients (91\%) in the current study underwent VAS compared to the initial study (none of the patients was subjected to VAS) on which the 12PUV signature is based. We have therefore slightly reorganized this paragraph and removed the phrase containing "tends to confirm" on page 8.

R2Q5: One of the limitations is the short follow-up period.

R2A5: We have added this limitation in the discussion on page 9.

R2Q5: Validating biomarkers in a separate cohort is a strength however the $\mathrm{n}$ is small. R2A5: We agree with this reviewer that the $\mathrm{n}$ is small. This was already mentioned in the original version of the manuscript as a study limitation in the discussion section. In addition, as discussed above in R2A2, we therefore reconsidered rewording this study as a "validation" study, and to employ the term "study of efficacy" throughout the revised manuscript. Biomarker validation will be performed in the large-scale ANTENATAL study $(n=400)$.

Reviewer \#3:

R3Q1: The authors should mention the parameters used to recommend VAS in fetuses with LUTO.

R3A2: Adequate changes were made to the text on page 4 stating "Because there are no definite predictive factors of pregnancy survival, just recommendations or suggestions, our team of gynecologists offered VAS as an option to all LUTO patients. Patients with confirmed classical symptoms during 2 separate ultrasound assessments (megabladder with or without bilateral hydronephrosis) and amniotic fluid reduction (AFI 8 or less) were qualified. Almost all approached patients opted for intervention."

R3Q2: I suggest to include a table showing the comparison between the first study and the present study in regard to ultrasonography findings, fetal urine biochemistry, performance of 12PUV and outcome.

R3A2: We have added this comparison in Table 2 in the revised version of the manuscript.

Editorial Office:

EO-Q1: Your methods section is largely copied from one of your previous papers. While this paper is OpenAccess, rather than just reusing the same text, please either 
rewrite, or refer to the methods 'as previously described in ... ' and cite the paper, then possibly adding a brief description.

EO-A1: The section "Fetal urinary peptidome analysis" in the methods section was rewritten as suggested in the revised version of the manuscript on page 4.

EO-Q2: Please supply your manuscript in an editable format, eg MS Word, rather than PDF

EO-A2: An MS Word version of the revised manuscript was submitted.

EO-Q3: Please revise your abstract to include the following category headings Background, Methods, Results, Conclusions EO-A3: We inserted these headings in the revised version of the abstract.

EO-Q4: Please include a conflict of interest statement in your manuscript. EO-A4: We have inserted the following COI on page 9 of the revised manuscript for Justyna Siwy (JS) "JS is an employee of Mosaiques diagnostics GmbH (Hannover, Germany) that markets urinary peptide-based diagnostics products."

EO-Q5: In your reference list, please ensure that journal titles are correctly abbreviated in line with Index Medicus, eg as used on PubMed EO-A5: We have double checked and correct abbreviations were used. E.g. ScientificWorldJournal is correct and is used as one word in Pubmed.

EO-Q6: Please define the abbreviations used in each table in table legends. EO-A6: Abbreviations were added to the table legends.

Comment to Editorial office:

For clarity, we added in the text and Table 1 the two patients that were lost in follow-up which were only mentioned in fi 
Dear Editor,

Thank you for sending out our manuscript entitled "Independent single center validation of a fetal urine peptide signature of postnatal renal outcome in fetuses with posterior urethral valves" by Buffin-Meyer and Tkaczyk et al, for review in Pediatric Nephrology.

We found the comments of the reviewers very helpful and we feel they have improved on the reporting of the study. We have replied point-by-point to all comments below and the major modifications have been introduced in the text with a bleu font.

The major changes are:

- Following the comment of reviewer 2 on the sample size, we have omitted the term "validation" from the entire manuscript since the study does not have enough power to use the term "validation. Validation was replaced by "study of efficacy" or similar wording.

- We wrongly defined the perinatal period and patients are now better divided in the perinatal (22 weeks of gestation to 7 days after birth) and the prenatal period.

- We obtained information on lesions other than in the kidney for the 3 patients that died in the perinatal period as requested.

- A comparison with the previous study has been added to Table 2 .

We hope that these modifications make the study suitable for publication in Pediatric Nephrology.

Best regards

Joost Schanstra

\section{Reviewers' comments:}

\section{Reviewer \#1:}

R1Q1: The authors should supply more clinical data on the patients that died in the perinatal period. Especially cause and time of death should be provided. The authors stated that cause of death was most likely severe renal disease but hypoplasia of the lungs may have accounted for several deaths in the perinatal period. Please clarify.

R1A1: Thank you for this comment.

- First of all we would like to correct the numbers of patients that died in the perinatal period (defined by 22 gestational weeks until 7 completed days after birth) which we did not define correctly in the first version of the manuscript. Taken into account this gestational age-range, only 3 patients died in the perinatal period. Hence this was corrected in the text on page 6 and in Table 1. - Indeed we obtained some information on the non-renal causes potentially involved in the death of those 3 patients in the perinatal period: "Three patients died in the perinatal period ( 2 patients died within the first 12 hours from delivery and 1 neonate died after 64 hours from delivery). These 3 patients had pulmonary insufficiency, renal insufficiency, secondary cardiac insufficiency with noresponse to resuscitation (ventilation) and vasopressors, and neurological complications (intracranial hemorrhage)." This has been added to the results section on page 6 and the comment on the absence of clinical data in the perinatal period was deleted from the discussion section. However no information on the prenatal death other than confirmation of PUV was obtained. 
R1Q2: Although the AUC of the ROC analysis carries the highest informative value, the authors should also provide sensitivity and specificity as achieved by the test's cut-off value as used in the results section.

R1A2: Sensitivity and specificity has been added to the results section using the cut-off values of the original STM study on page 6 and 7.

\section{Reviewer \#2:}

R2Q1: Introduction: Clarify how better predictors may affect management (prenatal counseling, postnatal follow up)

R2A1: We have introduced a paragraph in the introduction describing how improved prediction may affect management on page 3 .

R2Q2: Methods: How was simple size determined

R2A2: Thank you for this important remark that made us reconsider some of the wording in the manuscript.

We did not determine a sample size before starting the study, as the current study was an excellent opportunity to perform a preliminary but small independent "pre-validation" of the signature. As mentioned in the discussion of the manuscript, a large-scale international multicenter study, called ANTENATAL, is currently ongoing (finishing in 2023) aiming the multicenter validation of the 12PUV fetal urine peptide signature. The power calculation including loss of follow-up and refusal to participate in the ANTENATAL study estimated screening of $\sim 400$ patients with PUV for this study. This number is clearly not reachable by a single center for a rare disease such as PUV. Therefore we believe we have not correctly used the word "validation" throughout the current study since this should be reserved for the ANTENATAL study.

As indicated in the present work, the signature displayed similar efficacy in the current single center study to predict outcome compared to the initial STM study. We therefore omitted the word "validation" throughout the revised manuscript and replaced it by "study of efficacy" or similar wording.

R2Q3: Results: What is the value of including infants who didn't have confirmed PUV in the second analysis, this seems to be unnecessary.

R2A3: We respectfully disagree with this reviewer that including infants without confirmed PUV is unnecessary. In the clinical situation, where the use of the 12PUV signature is envisaged, management of the disease and parental counselling occur in the prenatal period where PUV is suspected but not yet confirmed (unless laser ablation of the valves is performed in utero). In most cases the presence of valves is only confirmed after birth. We believe that this justification is correctly worded in the discussion section but is only shortly described in the section where we present the results which might have not fully convinced this reviewer. Therefore, we have added an additional justification to the results section as well on page 7 .

R2Q4: Discussion: "The 12PUV fetal urine peptide signature-based prediction tends to confirm this by displaying absence of differences in the predictive capacity of the signature between patients that underwent VAS or not." This study was not intended to evaluate that outcome, besides it is a very small number for comparison.

R2A5: Although we agree that the study is small scale we believe that it is worth to point out that the majority of the patients (91\%) in the current study underwent VAS compared to the initial study (none of the patients was subjected to VAS) on which the 12PUV signature is based. We have therefore slightly reorganized this paragraph and removed the phrase containing "tends to confirm" on page 8.

R2Q5: One of the limitations is the short follow-up period. 
R2A5: We have added this limitation in the discussion on page 9.

R2Q5: Validating biomarkers in a separate cohort is a strength however the $\mathrm{n}$ is small.

R2A5: We agree with this reviewer that the $\mathrm{n}$ is small. This was already mentioned in the original version of the manuscript as a study limitation in the discussion section. In addition, as discussed above in R2A2, we therefore reconsidered rewording this study as a "validation" study, and to employ the term "study of efficacy" throughout the revised manuscript. Biomarker validation will be performed in the large-scale ANTENATAL study $(n=400)$.

\section{Reviewer \#3:}

R3Q1: The authors should mention the parameters used to recommend VAS in fetuses with LUTO. R3A2: Adequate changes were made to the text on page 4 stating "Because there are no definite predictive factors of pregnancy survival, just recommendations or suggestions, our team of gynecologists offered VAS as an option to all LUTO patients. Patients with confirmed classical symptoms during 2 separate ultrasound assessments (megabladder with or without bilateral hydronephrosis) and amniotic fluid reduction (AFI 8 or less) were qualified. Almost all approached patients opted for intervention."

R3Q2: I suggest to include a table showing the comparison between the first study and the present study in regard to ultrasonography findings, fetal urine biochemistry, performance of 12PUV and outcome.

R3A2: We have added this comparison in Table 2 in the revised version of the manuscript.

\section{Editorial Office:}

EO-Q1: Your methods section is largely copied from one of your previous papers. While this paper is OpenAccess, rather than just reusing the same text, please either rewrite, or refer to the methods 'as previously described in ... ' and cite the paper, then possibly adding a brief description.

EO-A1: The section "Fetal urinary peptidome analysis" in the methods section was rewritten as suggested in the revised version of the manuscript on page 4.

EO-Q2: Please supply your manuscript in an editable format, eg MS Word, rather than PDF EO-A2: An MS Word version of the revised manuscript was submitted.

EO-Q3: Please revise your abstract to include the following category headings - Background, Methods, Results, Conclusions

EO-A3: We inserted these headings in the revised version of the abstract.

EO-Q4: Please include a conflict of interest statement in your manuscript.

EO-A4: We have inserted the following COI on page 9 of the revised manuscript for Justyna Siwy (JS)

"JS is an employee of Mosaiques diagnostics $\mathrm{GmbH}$ (Hannover, Germany) that markets urinary peptide-based diagnostics products."

EO-Q5: In your reference list, please ensure that journal titles are correctly abbreviated in line with Index Medicus, eg as used on PubMed

EO-A5: We have double checked and correct abbreviations were used. E.g. ScientificWorldJournal is correct and is used as one word in Pubmed.

EO-Q6: Please define the abbreviations used in each table in table legends. 
EO-A6: Abbreviations were added to the table legends.

Comment to Editorial office:

For clarity, we added in the text and Table 1 the two patients that were lost in follow-up which were only mentioned in figure 1 in the initial version of the manuscript. 


\section{A single center study to evaluate the efficacy of a fetal urine peptide signature predicting postnatal renal outcome in fetuses with posterior urethral valves}

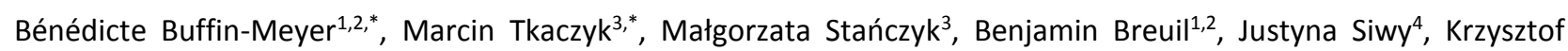
Szaflik ${ }^{5}$, Tomasz Talar ${ }^{6}$, Justyna Wojtera ${ }^{5}$, Waldemar Krzeszowski ${ }^{5}$, Stéphane Decramer ${ }^{1,2,7,8}$, Julie Klein ${ }^{1,2, * *}$, Joost P Schanstra ${ }^{1,2, * *}$

${ }^{1}$ Institut National de la Santé et de la Recherche Médicale (INSERM), U1048, Institut of Cardiovascular and Metabolic Disease, Toulouse, France.

${ }^{2}$ Université Toulouse III Paul-Sabatier, Toulouse, France.

${ }^{3}$ Department of Pediatrics, Immunology and Nephrology, Polish Mother's Memorial Hospital Research Institute, Lodz, Poland.

${ }^{4}$ Mosaiques diagnostics $\mathrm{GmbH}$, Hannover, Germany.

${ }^{5}$ Department of Genecology, Fertility and Fetal Therapy, Polish Mother's Memorial Hospital - Research Institute, Lodz, Poland

${ }^{6}$ Department of Neonatology, Polish Mother's Memorial Hospital - Research Institute, Lodz, Poland

${ }^{7}$ Service de Néphrologie Pédiatrique, Hôpital des Enfants, CHU Toulouse, Toulouse, France.

${ }^{8}$ Centre de Référence des Maladies Rénales Rares du Sud-Ouest (SORARE), Toulouse, France.

* Equal contribution

** Corresponding authors 


\section{Keywords}

Urinary proteome analysis, prenatal, prediction, outcome, chronic kidney disease, rare disease. 


\section{Introduction}

Posterior urethral valves (PUV) is a congenital anomaly associated with a wide spectrum of outcomes ranging from extremely severe phenotypes with prenatal death to live born children with normal renal function. Exclusively found in males, PUV is the major cause of severe obstructive nephropathy in children. Although a rare disease (ORPHA:93110, with a prevalence of 1-9 / 100000 ), it accounts for $17 \%$ of pediatric end-stage renal disease (ESRD) [1-3].

The management of PUV is hampered by the absence of tools for adequate antenatal screening of PUV fetuses at high risk for developing renal failure. Current clinical practice is based on prenatal ultrasound and fetal urine biochemistry but this is clearly insufficient to predict postnatal renal outcome with any accuracy in PUV patients as shown in several (meta) studies [4, 5]. This lack of efficient prognostic methods leads to many parents opting for termination of pregnancy [4-6]. Better predictors would allow adequate selection of fetuses that would potentially benefit from prenatal intervention (vesicoamniotic shunting (VAS) or laser ablation of valves). In addition, when predicted in the high-risk stratum, clear-cut knowledge of the outcome of the disease will give time to the future parents to psychologically accept [7] the fact that they will have a child with chronic, potentially severe disease and decide whether they would like their newborn to be offered palliative care or renal replacement therapies (i.e. dialysis or transplantation) [8]. Hence, new predictive strategies are necessary to allow optimal diagnostic and therapeutic management of the disease.

Urinary peptidome analysis has emerged as a potent tool for the discovery and validation of biomarkers of renal disease [9], both in adults [10,11] and in children [12-14]. In the setting of PUV, we identified a fetal urinary peptide signature called 12PUV that predicted in utero the postnatal renal function of PUV fetuses with high accuracy [15], outperforming routine ultrasound and fetal urine biochemistry. Here, as a first step in the validation process, we evaluated the accuracy of the 12PUV signature to predict postnatal renal outcome in an independent single center study including 33 suspected PUV pregnancies. 


\section{Material and Methods}

Clinical data and sample collection

Patients were included in the study upon suspicion of PUV due to the presence of a megabladder and/or oligohydramnios/anhydramnios. Prenatal ultrasound findings obtained the time of fetal urine sampling were recorded. The study endpoint was the renal status after 6 months of postnatal follow-up. For live born children, renal function was estimated at 6 months of age using serum creatinine concentrations according the Schwartz method [16]. Because there are no definite predictive factors of pregnancy survival - just recommendations or suggestions -, our team of gynecologists offered VAS as an option to all patients with lower urinary tract obstruction (LUTO). Patients with confirmed megabladder (with or without bilateral hydronephrosis) and amniotic fluid reduction (AFI 8 or less) during 2 separate ultrasound assessments qualified for intervention. Almost all approached patients opted for intervention.

The study was performed in accordance with the Declaration of Helsinki [17] and with Good Clinical Practice guidelines. The research was approved by the local (Lodz, Poland) ethics committee $\left(N^{\circ} 1 / 2016\right)$ and informed consent was obtained from each participant.

\section{Fetal urinary peptidome analysis}

Fetal urine was collected from the bladder of the fetus under ultrasound guidance and directly frozen. Samples were shipped on dry-ice to Toulouse (France). Samples were prepared for capillary electrophoresis coupled to mass spectrometry (CE-MS) analysis as described in detail [15]. Briefly, proteins were eliminated by dilution of the fetal urine sample in ammonium hydroxide buffer containing SDS to decrease the interaction of peptides and proteins followed by centrifugation using a 20-kDa cut-off filter. In the next step salts were removed from the filtrate by gel filtration followed by lyophilization of the sample. The lyophilized samples were stored at $4^{\circ} \mathrm{C}$ until use.

Shortly before CE-MS analysis, samples were re-suspended in $10 \mu \mathrm{L}$ HPLC-grade water. CE-MS analyses were performed as previously described [15]. Briefly, CE-MS analyses were performed using a Beckman Coulter Proteome Lab PA800 capillary electrophoresis system on-line coupled, using an electro-ionization sprayer (Agilent Technologies), to a micrOTOF II MS (Bruker Daltonic). Spectra were accumulated every 3 $\mathrm{s}$, over a range of $\mathrm{m} / \mathrm{z} 350$ to 3000 .

Mass spectral ion peaks representing identical molecules at different charge states were deconvoluted into single masses using MosaiquesVisu software as described [18]. CE migration time was calibrated by local regression using over 1700 reference signals. Normalization of the amplitude of the fetal urine peptides is based on sequenced endogenous "housekeeping" peptides as described in [15]. Raw peptide data for each sample can be found in the Supplementary Table 1. 
AUCS of the previously defined [15] biomarker model and 95\% confidence intervals $(95 \% \mathrm{Cl}$ ) were calculated using receiver operating characteristic (ROC) plots (MedCalc version 19.0.3, MedCalc Software). Paired comparison of ROC curves was also carried out in MedCalc using one-sided tests and according to [19] in order to evaluate whether the fetal urine peptide signature outperformed clinical parameter-based prediction. A one-sided P-value $<0.05$ was considered as statistically significant. 


\section{Results}

\section{Study population}

Patients were recruited in the Lodz region (Poland) from January 2016 to September 2017. Thirty-three patients were included in the study on the basis of PUV suspicion (Figure 1). PUV was confirmed after birth in 23 patients (Table 1).

In these confirmed PUV pregnancies, the major cause for the discovery of PUV was the presence of a megabladder (83\%). Most kidneys showed increased echogenicity (70\%) and $57 \%$ of the pregnancies presented oligohydramnios. All but two (91\%) patients received a vesicoamniotic shunt (VAS, Table 1).

Evaluation of the predictive performance of the 12PUV fetal urinary signature in patients with postnatally confirmed PUV

Ninety one \% (21/23) of the patients with postnatally confirmed PUV were followed up to the age of 6 months postnatally (Figure 1A). This time of follow-up is much shorter than in the initial study where we identified the 12PUV predictive peptide model based on an end point of ESRD at two years of age [15]. Therefore the end-point in the current study was modified to prenatal and perinatal death or at least stage 3 CKD at postnatal month 6 (eGFR<60 mL/min/1.73, Schwartz formula), considering that having CKD stage 3 renal disease at 6 months is a predisposition to progress to severe renal failure at 2 years of age. Four patients died in the prenatal period (at $16(n=2), 19$ and 21 gestational weeks). Three patients died in the perinatal period ( 2 patients died within the first 12 hours from delivery and 1 neonate died after 64 hours from delivery). These 3 patients had pulmonary insufficiency, renal insufficiency, secondary cardiac insufficiency with no-response to resuscitation (ventilation) and vasopressors, and neurological complications (intracranial hemorrhage). Nine live-born had CKD stage $\geq 3$ (mean GFR: 26, range 5-47, $\mathrm{mL} / \mathrm{min} / 1.73$ ) and 5 others had a normal or moderately reduced renal function (CKD stage $<3$, mean GFR: 95 , range $68-130, \mathrm{~mL} / \mathrm{min} / 1.73$ ) at 6 months postnatally (Table 1 ).

Application of the previously identified 12PUV fetal urine peptide signature to this new, temporally and geographically, independent cohort classified the patients based on their postnatal renal outcome with an AUC $0.94(95 \% \mathrm{Cl}: 0.74-1.00)$, similar to the predictive values of the original study (AUC of 0.94 [15]) (Figure 2). Using the cut-off 12PUV score of 0 as previously defined [15], the sensitivity was $100 \%$ ( $95 \% \mathrm{Cl}$ : 79-100) and the specificity was $60 \%(95 \% \mathrm{Cl}: 15-95)$. The low specificity, as exemplified by the large confidence interval, is due to the low number of PUV pregnancies with a favorable outcome. However, the overall resulting accuracy of $90 \%(95 \% \mathrm{Cl}: 78-100)$ is again close to the calculated accuracy of the previous study of $92 \%$ (95\% Cl: 84-100).

Comparison of the predictive capacity of the fetal urine peptide signature with the clinical parameters showed that the fetal urine peptide signature predicted with a higher AUC postnatal renal outcome 
(Table 2), except for AF volume where the significance was not reached $(p=0.06)$. Again similar to the initial study [15].

Use of the signature in the context of suspected PUV

The context in which the 12PUV signature was developed is not entirely representing the clinical situation encountered. Indeed one would need to predict the postnatal renal outcome in the prenatal period in "suspected PUV" instead of "confirmed PUV pregnancies" since the presence of valves is only confirmed after birth in the majority of the cases. We therefore re-analyzed the performance of the 12PUV signature adding the 10 postnatally non-confirmed suspected PUV fetal urine samples (Figure 1B). Interestingly, in this context the predictive value of the 12PUV signature was close to that measured for the confirmed PUV pregnancies with an AUC $0.89(95 \% \mathrm{Cl}$ : 0.72-0.97) (Figure 3). Again when using the cut-off 12PUV score of 0 as defined in the original study [15], sensitivity was high $(92 \%(95 \% \mathrm{Cl}$ : $74-99)$ and specificity was low with a large confidence interval $(50 \%(95 \% \mathrm{Cl}$ : $12-88))$, but resulting in an accuracy of $84 \%(95 \% \mathrm{Cl}: 71-$ 97) 


\section{Discussion}

In the current independent single center study we observed that the previously identified 12PUV fetal urine peptide signature predicted with high precision postnatal renal outcome in fetuses with PUV. An important aspect of the current work is that this is an independent study with respect to: i) time of recruitment (several years separate the studies), ii) independence of the recruiting center (the Lodz center did not participate in the original study), and iii) the geographical origin of the patients (the patients from the original study all came from France while the current patients all come from Poland). This small scale single center study is therefore an important premise for the recently started prospective large-scale study, named ANTENATAL (clinicaltrials.gov NCT03116217; "multicentre vAlidatioN of a fetal urine pepTidome-based classifiEr to predict postnatal reNAl function in posterior ureThral vALves"), aiming to validate the peptide signature in a much larger multicenter setting. The ANTENATAL trial will enroll 400 PUV pregnancies screened in $>30$ European centers with involvement of two large European Reference Networks on rare diseases over a period of 4 years and with a patient follow-up until the child's age of 2 years [20]. The ANTENATAL study will also be an excellent opportunity to evaluate the potential of adding other fetal urinary omics traits to peptide markers for kidney disease stratification, including proteins, metabolites and miRNAs, as we observed in a recent study [21] based on a recently developed urinary metabolome analysis pipeline [22]. In addition, the ANTENATAL trial will allow exploring the possibility of extending the omics analysis to amniotic fluid for a less invasive prediction of postnatal renal function in PUV pregnancies.

The majority of the confirmed PUV patients in the current work underwent VAS (91\%), while none of the fetuses were subjected to VAS in the previous study. Although several studies suggest that VAS is beneficial for the perinatal renal survival, it appears that it is not modifying the long-term ( $>6$ months) outcome [23] since the 12PUV signature displayed similar predictive capacity of postnatal renal outcome 6 months after birth in both current and previous studies.

The 12PUV signature was designed in the context of lower urinary tract obstruction (LUTO) with the focus on PUV, being the most frequently encountered etiology. However, unless laser ablation of the valves is performed in utero allowing the confirmation of PUV prenatally, the presence of valves is only confirmed after birth. Therefore, to be of clinical utility, the signature has also to perform well in any suspected PUV (i.e. in all LUTO). Indeed, we observed that the 12PUV signature displayed excellent predictive capacity in the suspected PUV population. This might be explained by the fact that the 12PUV peptide signature, for the major part composed of collagen fragments, is most likely not representing the molecular signature of the bladder obstruction, but more likely the molecular changes due to tissue remodeling in the kidney as exemplified by the presence of dys/hypoplasia, cysts etc... in LUTO. We have observed similar molecular changes in amniotic fluid of congenital anomalies of the kidney and the urinary tract that were also independent of the underlying etiology (Klein, Buffin-Meyer et al., unpublished observations). 
The present study has several limitations. The study is single center and uses a relatively small cohort with short follow-up. However, it should be kept in mind that PUV is a rare disease (ORPHA:93110) with a prevalence of 1-9/100 000. Such limitations should be removed in the future by the ongoing multicenter ANTENATAL study [20]. In addition, although fetal biochemistry was performed (sodium and chloride), fetal urine $\beta 2$-microglobulin, known to be also associated to postnatal renal outcome in PUV [24], was not available for comparison.

In conclusion we have observed in an independent study that the previously identified 12PUV fetal urine peptide signature predicted with high precision the postnatal renal outcome in fetuses with confirmed PUV. The signature also performed very well in suspected PUV pregnancies with an AUC of 0.89 .

\section{Funding sources}

The study was supported by Polish Mothers Memorial Hospital Research Institute (internal grant number 2016/IV/54-GW), by the "Fondation pour la Recherche Médicale" (grant number DEQ20170336759) and by the "Agence de la Biomédecine" (METAPhOR project).

\section{Conflict of interest}

JS is an employee of Mosaiques diagnostics GmbH (Hannover, Germany) that markets urinary peptidebased diagnostics products. 


\section{References}

1. Agarwal S (1999) Urethral valves. BJU international 84:570-578.

2. Hodges SJ, Patel B, McLorie G, Atala A (2009) Posterior urethral valves. ScientificWorldJournal 9:1119-1126.

3. Krishnan A, de Souza A, Konijeti R, Baskin LS (2006) The anatomy and embryology of posterior urethral valves. J Urol 175:1214-1220.

4. Morris RK, Quinlan-Jones E, Kilby MD, Khan KS (2007) Systematic review of accuracy of fetal urine analysis to predict poor postnatal renal function in cases of congenital urinary tract obstruction. Prenat Diagn 27:900-911.

5. Morris RK, Malin GL, Khan KS, Kilby MD (2009) Antenatal ultrasound to predict postnatal renal function in congenital lower urinary tract obstruction: systematic review of test accuracy. BJOG 116:1290-1299.

6. Hogan J, Dourthe ME, Blondiaux E, Jouannic JM, Garel C, Ulinski T (2012) Renal outcome in children with antenatal diagnosis of severe CAKUT. Pediatr Nephrol 27:497-502.

7. Stevenson DK, Goldworth A (1998) Ethical dilemmas in the delivery room. Semin Perinatol 22:198206.

8. Lantos JD, Warady BA (2013) The evolving ethics of infant dialysis. Pediatr Nephrol 28:1943-1947.

9. Klein J, Bascands JL, Mischak H, Schanstra JP (2016) The role of urinary peptidomics in kidney disease research. Kidney Int 89:539-545.

10. Schanstra JP, Zurbig P, Alkhalaf A, Argiles A, Bakker SJ, Beige J, Bilo HJ, Chatzikyrkou C, Dakna M, Dawson J, Delles C, Haller H, Haubitz M, Husi H, Jankowski J, Jerums G, Kleefstra N, Kuznetsova T, Maahs DM, Menne J, Mullen W, Ortiz A, Persson F, Rossing P, Ruggenenti P, Rychlik I, Serra AL, Siwy J, Snell-Bergeon J, Spasovski G, Staessen JA, Vlahou A, Mischak H, Vanholder R (2015) Diagnosis and Prediction of CKD Progression by Assessment of Urinary Peptides. J Am Soc Nephrol 26:1999-2010.

11. Pontillo C, Jacobs L, Staessen JA, Schanstra JP, Rossing P, Heerspink HJL, Siwy J, Mullen W, Vlahou A, Mischak H, Vanholder R, Zurbig P, Jankowski J (2017) A urinary proteome-based classifier for the early detection of decline in glomerular filtration. Nephrol Dial Transplant 32:1510-1516.

12. Decramer S, Wittke S, Mischak H, Zurbig P, Walden M, Bouissou F, Bascands JL, Schanstra JP (2006) Predicting the clinical outcome of congenital unilateral ureteropelvic junction obstruction in newborn by urinary proteome analysis. Nat Med 12:398-400.

13. Drube J, Zurbig P, Schiffer E, Lau E, Ure B, Gluer S, Kirschstein M, Pape L, Decramer S, Bascands JL, Schanstra JP, Mischak H, Ehrich JH (2010) Urinary proteome analysis identifies infants but not older children requiring pyeloplasty. Pediatr Nephrol 25:1673-1678.

14. Schanstra JP, Mischak H (2015) Proteomic urinary biomarker approach in renal disease: from discovery to implementation. Pediatr Nephrol 30:713-725.

15. Klein J, Lacroix C, Caubet C, Siwy J, Zuerbig P, Dakna M, Muller F, Breuil B, Stalmach A, Mullen W, Mischak H, Bandin F, Monsarrat B, Bascands J-L, Decramer S, Schanstra JP (2013) Fetal Urinary Peptides to Predict Postnatal Outcome of Renal Disease in Fetuses with Posterior Urethral Valves (PUV). Science translational medicine 5.

16. Schwartz GJ, Munoz A, Schneider MF, Mak RH, Kaskel F, Warady BA, Furth SL (2009) New equations to estimate GFR in children with CKD. J Am Soc Nephrol 20:629-637.

17. (1997) World Medical Association declaration of Helsinki. Recommendations guiding physicians in biomedical research involving human subjects. JAMA 277:925-926.

18. Neuhoff N, Kaiser T, Wittke S, Krebs R, Pitt A, Burchard A, Sundmacher A, Schlegelberger B, Kolch $W$, Mischak H (2004) Mass spectrometry for the detection of differentially expressed proteins: a comparison of surface-enhanced laser desorption/ionization and capillary electrophoresis/mass spectrometry. Rapid Commun Mass Spectrom 18:149-156.

19. DeLong ER, DeLong DM, Clarke-Pearson DL (1988) Comparing the areas under two or more correlated receiver operating characteristic curves: a nonparametric approach. Biometrics 44:837845. 
20. Buffin-Meyer B, Klein J, van der Zanden LFM, Levtchenko E, Moulos P, Lounis N, Conte-Auriol F, Hindryckx A, Wühl Et, Persico N, Oepkes O, Schreuder M, Tkaczyk M, G. A, M. F, Parvex P, Feitz W, Olsen H, Montini G, Decramer S, Schanstra JP, ANTENATAL Tc (2019) The ANTENATAL multicenter study to predict postnatal renal outcome in fetuses with posterior urethral valves: objectives and design. Clin Kidney J in press.

21. Buffin-Meyer B, Klein J, Breuil B, Muller F, Moulos P, Groussolles M, Bouali O, Bascands JL, Decramer S, Schanstra JP (2018) Combination of the fetal urinary metabolome and peptidome for the prediction of postnatal renal outcome in fetuses with PUV. Journal of proteomics 184:1-9.

22. Boizard F, Brunchault V, Moulos P, Breuil B, Klein J, Lounis N, Caubet C, Tellier S, Bascands JL, Decramer S, Schanstra JP, Buffin-Meyer B (2016) A capillary electrophoresis coupled to mass spectrometry pipeline for long term comparable assessment of the urinary metabolome. Sci Rep 6:34453.

23. Nassr AA, Shazly SAM, Abdelmagied AM, Araujo Junior E, Tonni G, Kilby MD, Ruano R (2017) Effectiveness of vesicoamniotic shunt in fetuses with congenital lower urinary tract obstruction: an updated systematic review and meta-analysis. Ultrasound in obstetrics \& gynecology : the official journal of the International Society of Ultrasound in Obstetrics and Gynecology 49:696703.

24. Dreux S, Rosenblatt J, Moussy-Durandy A, Patin F, Favre R, Lortat-Jacob S, El Ghoneimi A, Oury JF, Deschenes G, Ville Y, Heidet L, Muller F (2018) Urine biochemistry to predict long-term outcomes in fetuses with posterior urethral valves. Prenat Diagn 38:964-970. 


\section{Table 1}

\begin{tabular}{|c|c|}
\hline Study population & $\mathrm{N}=\mathbf{2 3}$ \\
\hline Gestational age at discovery of PUV, weeks (median [range]) & $21[13-28]$ \\
\hline Megabladder, number & 19 \\
\hline Keyhole, number & 17 \\
\hline Prenatal death, number & 4 \\
\hline Perinatal death, number & 3 \\
\hline Lost in postnatal follow-up & 2 \\
\hline Survivors at 6 months, number & 14 \\
\hline \multicolumn{2}{|l|}{ CKD stage $\geq 3$} \\
\hline number & 9 \\
\hline eGFR, $\mathrm{mL} / \mathrm{min} / 1.73 \mathrm{~m}^{2}$ (median [range]) & $26[5-47]$ \\
\hline \multicolumn{2}{|l|}{ CKD stage $<3$} \\
\hline number & 5 \\
\hline eGFR, $\mathrm{mL} / \mathrm{min} / 1.73 \mathrm{~m}^{2}$ (median [range]) & 95 [68-130] \\
\hline \multicolumn{2}{|l|}{ Ultrasound: kidney abnormalities } \\
\hline Normal, number & 2 \\
\hline Increased echogenicity, number & 16 \\
\hline Cysts, number & 6 \\
\hline Not available, number & 1 \\
\hline \multicolumn{2}{|l|}{ Ultrasound: amniotic fluid volume } \\
\hline Normal, number & 7 \\
\hline Oligohydramnios, number & 13 \\
\hline Anhydramnios, number & 3 \\
\hline \multicolumn{2}{|l|}{ Fetal urine biochemistry } \\
\hline Sodium, mM (median [range]) & $101[75-146]$ \\
\hline Chloride, mM (median [range]) & $86[53-146]$ \\
\hline Osmolality, mOsm/kg [median (range]) & 203 [96-269] \\
\hline Patients receiving vesicoamniotic shunts, number & 21 \\
\hline $\begin{array}{l}\text { Gestational age when receiving vesicoamniotic shunts, } \\
\text { weeks (median [range]) }\end{array}$ & $21[13-30]$ \\
\hline
\end{tabular}

Abbreviations: PUV, posterior urethral valves; CKD, chronic kidney disease; eGFR, estimated glomerular filtration rate. 
Table 2

Comparison of the 12PUV fetal urine peptide signature predictive performance with clinical parameters in postnatally confirmed PUV pregnancies and comparison with previous study in 2013 [15].

\begin{tabular}{|l|l|l|l|l|}
\hline & \multicolumn{2}{|c|}{ Current study } & \multicolumn{2}{c|}{ Previous 2013 study* } \\
\hline & AUC (95\%Cl) & $\begin{array}{l}\text { One sided P- } \\
\text { value** }\end{array}$ & AUC (95\%CI) & $\begin{array}{l}\text { One sided P- } \\
\text { value** }\end{array}$ \\
\hline 12 PUV & $0.94(0.74-1.00)$ & & $0.94(0.82-0.99)$ & \\
\hline Fetal urine sodium & $0.70(0.46-0.88)$ & 0.031 & $0.78(0.62-0.90)$ & 0.025 \\
\hline Fetal urine chloride & $0.70(0.46-0.88)$ & 0.042 & Not available & - \\
\hline Fetal urine osmolality & $0.72(0.48-0.89)$ & 0.041 & Not available & - \\
\hline Reduced AF volume & $0.81(0.58-0.94)$ & 0.061 & $0.53(0.36-0.69)$ & $<0.0001$ \\
\hline Increased echogenicity & $0.69(0.45-0.87)$ & 0.0009 & $0.56(0.39-0.72)$ & $<0.0001$ \\
\hline Cysts & $0.56(0.33-0.77)$ & $<0.0001$ & $0.63(0.46-0.78)$ & $<0.0001$ \\
\hline
\end{tabular}

* Using the 38 patients of the validation set of the 2013 study [15]; ** Versus 12PUV; Abbreviations: 12PUV, 12 fetal urine peptide signature previously identified in [15]; AF volume, amniotic fluid volume. 


\section{Figure legends}

Figure 1: Description of patient flow and fetal urine peptidome analysis of PUV pregnancies with A) postnatally confirmed PUV and B) all suspected PUV pregnancies.

Figure 2: ROC curve of the prediction of postnatal renal outcome (severe versus normal to moderately reduced renal function) of confirmed PUV pregnancies ( $n=21)$ at 6 months postnatally by the previously established 12PUV fetal urinary peptide signature [15].

Figure 3: ROC curve of the prediction of postnatal renal outcome (severe versus normal to moderately reduced renal function) of all suspected PUV pregnancies ( $n=31)$ at 6 months postnatally by the previously established 12PUV fetal urinary peptide signature [15]. 


\section{Supplementary Tables}

1

2

3

4

5

6

7

8

9

10

11

12

13

14

15

16

17

18

19

20

21

22

23

24

25

26

27

28

29

30

31

32

33

34

35

36

37

38

39

40

41

42

43

44

45

46

47

48

49

50

51

52

53

54

55

56

57

58

59

60

61

62

63

64

65

Supplementary Table: Normalized abundance of each of the 5616 fetal urinary peptides in each sample. 
33 women carrying fetuses with suspected PUV were included in the study

33 fetal urine samples were analysed and scored with the 12PUV signature

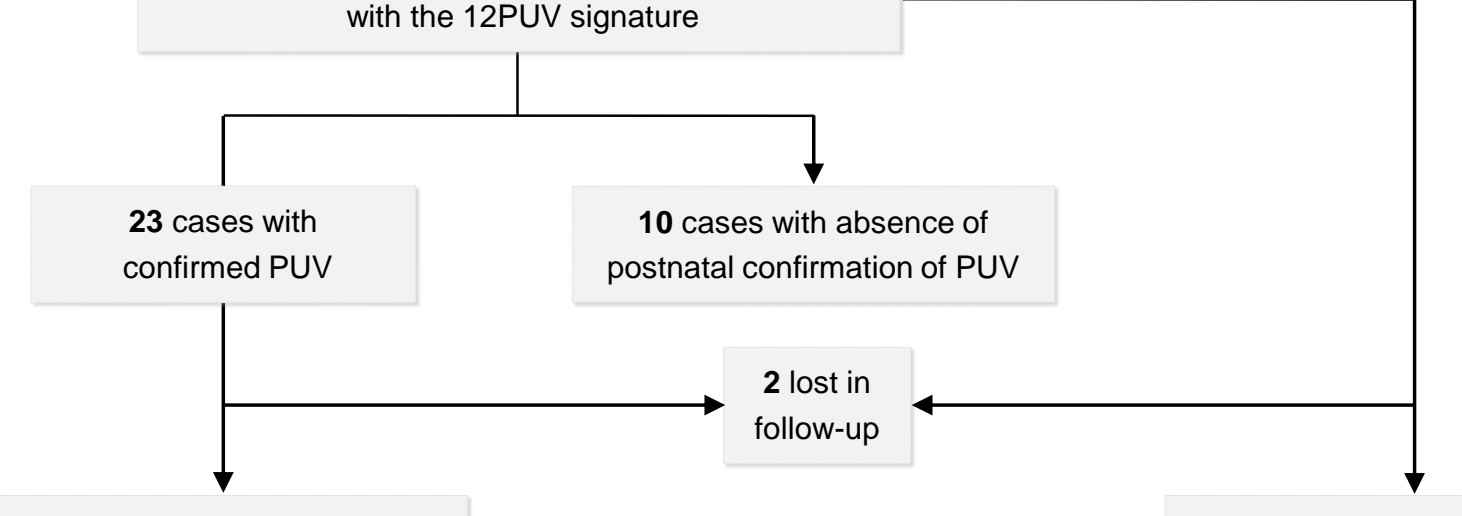

21 cases with renal outcome 6 months after birth

31 cases with renal outcome 6 months after birth

A) Used for validation of the 12PUV signature of "confirmed PUV"

B) Used for validation of the 12PUV signature of "suspected PUV"

\section{Figure 1}




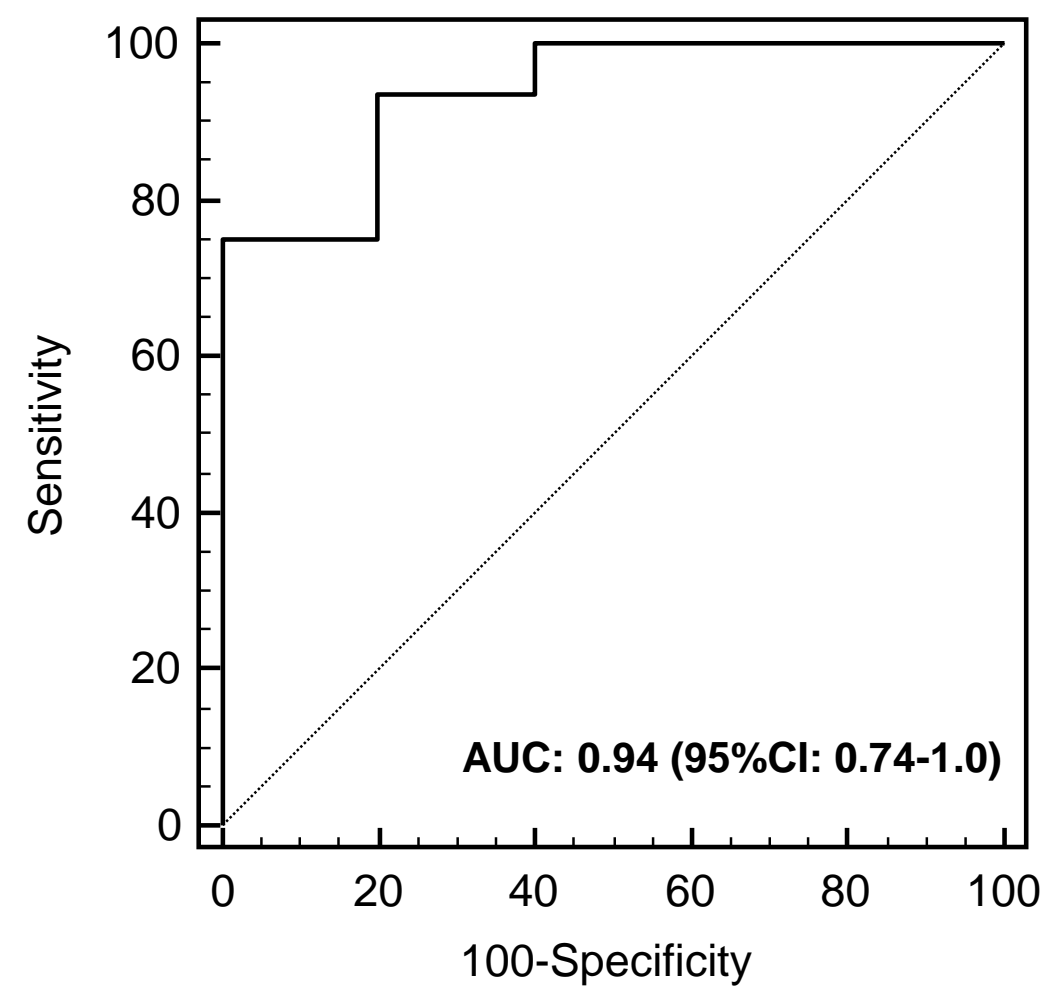

Figure 2 


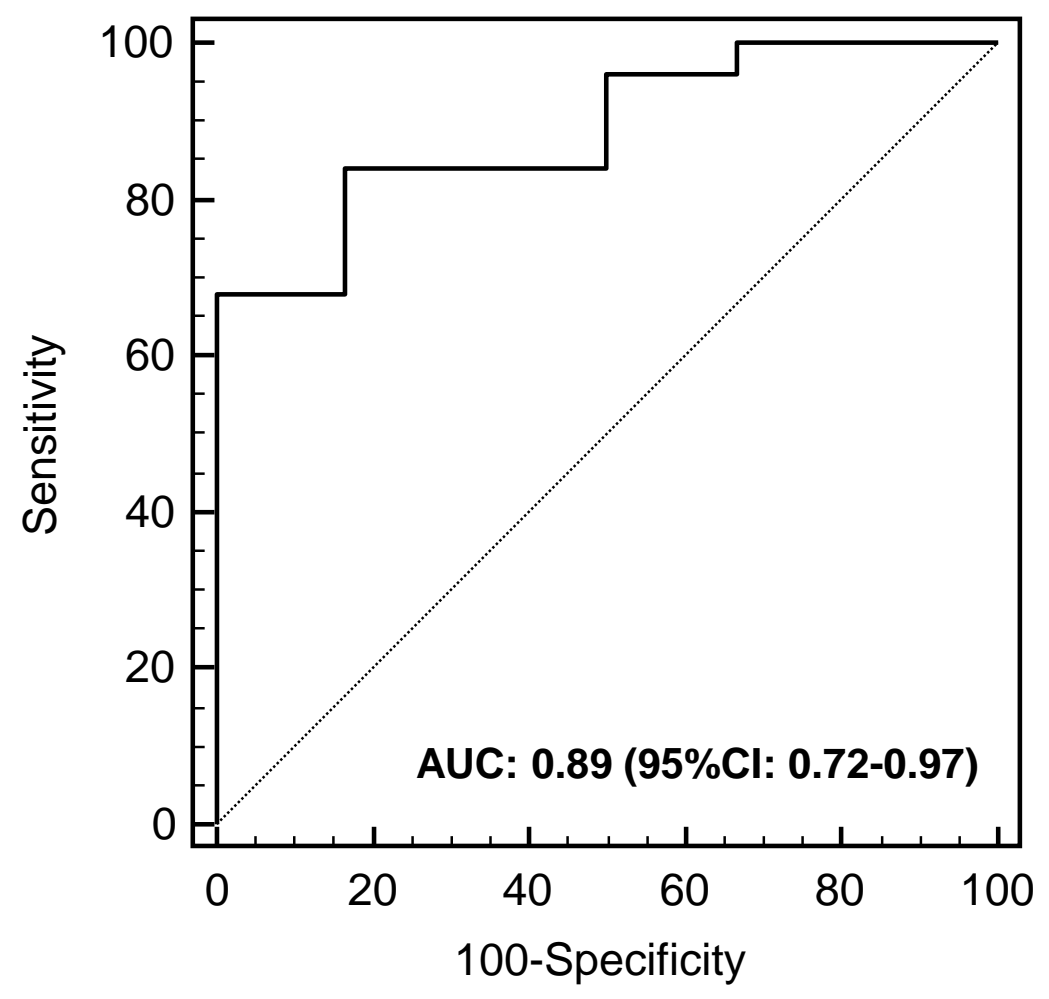

Figure 3 
Click here to access/download Supplementary Material Supplementary table final_wo center codes.xlsx 